\title{
Challenges and Opportunity of Performance Policy Implementation in Facing New Normal Era
}

\author{
Septiana Dwiputrianti ${ }^{1}$, Dina Rahma Adila ${ }^{2}$ \\ Indonesian Civil Service Commission, Pancoran, Jakarta Selatan, Indonesia ${ }^{12}$ \\ \{tiana.dwi@kasn.go.id ${ }^{1}$, dina.rahma@kasn.go.id²\}
}

\begin{abstract}
Human Development is one of the priorities of the Indonesian government for the year 2021-2024. The Performance Management Policy, which was just issued in 2020, is one of the breakthroughs to support human resource apparatus reform. However, data shows that there are still many obstacles faced for its implementation, especially in facing a new normal era at some local governments. This study contributes to ongoing evaluation and solutions in improving government performance through improving the performance of its apparatus. Various documents and data related to the implementation of performance management will be investigated to establish a mapping of problems and constraints, as well as alternative solutions. Using various supporting documents from various agencies both at the central and regional levels, various efforts and obstacles can be shown. Some of the challenges that are still being faced are given alternative solutions that can be applied to overcome these performance problems.
\end{abstract}

Keywords: Policy Implementation; Performance Management; New Normal; Indonesia

\section{Introduction}

Bureaucratic Reforms for 2020-2024 contained in the 2020-2024 National Medium Term Development Plan (RPJMN) and Strategic Plan of the Ministry of Administrative and Bureaucratic Reform in the Ministerial Regulation of Administrative and Bureaucratic Reform Number 24 of 2020 [1], one of which focuses on Reforms related to the Human Resources (HR) Apparatus Development. HR management is a formal system to ensure that existing resources are used efficiently and effectively in achieving organizational objectives within an organization. HR management is built to develop and motivate employees so that they can provide the best contribution in achieving the organization's mission [2].

The efforts to improve HR Apparatus Management in Bureaucratic Reform are carried out by implementing the merit system as National Development. This cannot be separated from the improvement of the performance management system of HR Apparatus as one of the main aspects in the merit system implementation [3]. Performance management encounters various obstacles both in its planning and implementation.

According to Indonesian Civil Service Commission (KASN) Regulation Number 3 of 2020 about Strategic Plan of Indonesian Civil Service Commission for 2020-2024 [4], 
Indonesian Civil Service Commission (KASN) is the institution responsible for supervising the implementation of a merit system as HR Apparatus Management, including performance management, in Indonesia [5]. Based on KASN's experience in supervising the implementation of Law No. 5 of 2014 on State Civil Apparatus, the weak performance management system in government institutions in the implementation of the merit system, such as the consistent implementation of Government Regulation Number 46 Year 2011 on the Civil Servant Performance Appraisals, is one of some problems or obstacles in implementing the policy [6].

The territory of Indonesia, which covers a large area, the condition of infrastructure development, as well as the quality and quantity of HR that have not been evenly distributed, have become a significant obstacle in improving the performance management of the HR Apparatus. Hindrances related to performance management need to be mapped and evaluated to perceive solutions to diversified problems in each condition in various regions in Indonesia.

Merit system implementations in underdeveloped areas which cover cities and regencies in Kalimantan, Sulawesi, Sumatera, Maluku, Papua, and even several remote areas in Java are still poor [7]. Major partiality between central government agencies such as ministries and national institutes, and cities or regencies in underdeveloped areas in Indonesia portrays the implementation of HR performance management as an aspect of meritocracy. The poor implementations are depicted in the ineffectiveness of performance measurement which can be seen from the poorness of Performance Contracts; Performance Appraisal Methods; Performance Dialogues; Gap Performance Analysis; and Use of the Performance Appraisal for Career Development and Decisions.

Referring to the Ministerial Regulation of Administrative and Bureaucratic Reform Number 8 of 2021 concerning the Performance Management System for Civil Servants [8], the performance management system for civil servants is implemented based on the following principles: Objectives; Measurable; Accountable; Participatory; and Transparent. The civil service performance management system consists of: Performance Planning; Performance Implementation, Performance Monitoring, and Performance Coaching; Performance assessment; Follow-up; and Civil Service Performance Information System.

Performance management is a set of systematic attempts, initiatives, and processes to measure, monitor, and evaluate intended achievements [9]. The measurement procedure for public sphere performance can be seen through the conceptualization of performance indicators. The conceived workload of the performance information forms the configuration of the measurement system. The performance information utilization is more efficient when it is integrated into the scheme and management [10].

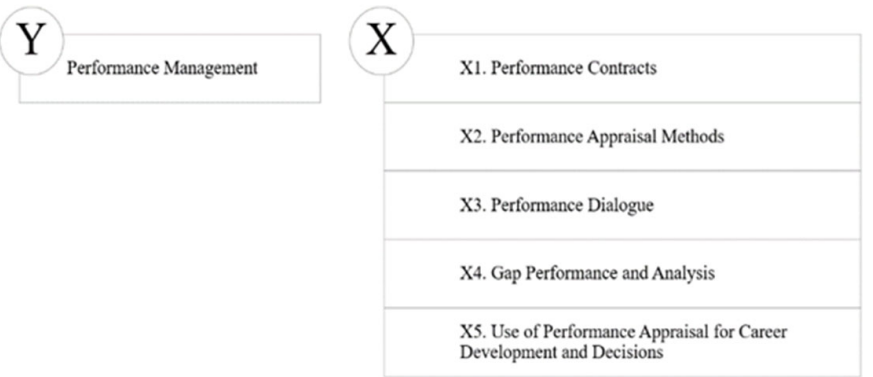

Fig 1. Performance Management Indicators (Source: Proceed from Ministerial

Regulation of Administrative and Bureaucratic Reform Number 40 of 2018 and Indonesian

Civil Service Commission (KASN) Regulation Number 9 of 2019) 
Meanwhile, indicators for implementing good Performance Management as one of the eight Merit System aspects [11] include:

a. Availability of measurable performance contracts derived from the organization's Strategic Plan;

b. Use of objective performance appraisal methods;

c. Implementation of periodic performance appraisals accompanied by performance dialogues to ensure the achievement of performance contracts;

d. Availability of information on the analysis of performance problems and the preparation of strategies for solving them to achieve organizational goals; and

e. Use of performance appraisal results in making decisions related to career coaching and development.

Addressing primarily the technical difficulties can be seen as an evaluation strategy to improve performance management [9]. Performance in recent years is a highly prominent notion among those around the world who administer public management. As government agencies and other organizations have strived to deliver results under conditions of austerity, managing performance has acquired even more importance [12]. In times of crisis, the interactions of environmental conditions and organizational variables through decision-making management are particularly crucial. Crises provide huge demands on organizational needs for resources, such as information, funds, and technology. Increasing control during crises emphasizing the need for structural flexibility in an integrated response system has been long noted [13].

The dynamics of the development of business organization relationships need to be a lesson for organizations to continue to transform and adapt in order to face crises and take advantage of existing opportunities. Organizational transformation needs to be directed towards change. Conducive new designs continue to develop and manage innovation, manage risk, organizational integration in building synergy and collaboration. Changes in organizational structure, communication and coordination processes, as well as removing structural barriers are needed to make the growth and development of creativity in organizational-level innovation. To answer the uncertainty of the strategic environment of an increasingly dynamic and complex organization, the organizational structure needs to be continuously transformed towards an organic organization, characterized by low formalization, cross-functional teams, and freeflowing information [14].

In organizational transformation, the development of measurable visionary transformational leadership at various levels of leadership in the organization there needs to be in order to align the vision and internal environment that is balanced with the ability to respond to changes in the external environment that is moving fast in the era of the Industrial Revolution 4.0, as well as ensuring that every innovation developed can add value to the quality of service. Organizational transformation emphasizes fundamental changes in work patterns, organizational culture and developed strategic values, not just procedural. Organizational transformation plays a strategic role in institutional (institutional) approaches, in increasing competitiveness, administrative 'traffic' where organizational transformation with governance and work culture is a determining factor for success [14].

A planned and measurable transformation in the development of organizational institutions is urgently needed in responding to problem statements that generally characterize organizational weaknesses, which are deemed necessary to increase transparency, responsiveness, and build accessible performance mechanisms so as to allow "checks and balances". Organizational transformation is greatly influenced: leadership style, work 
processes, work force, work culture, organizational structure that can increase the speed of service, increase competitiveness, and be adaptive to change. Organizational transformation needs to be followed by a change in mindset that prioritizes performance measurement and improves performance focusing on: goals, outcomes and outputs, by utilizing technology and information systems in building leadership at various levels, so as to control the planning stages of monitoring, evaluating, and reporting [14].

Performance measurement shrinks the complex operation of a professional entity to its fundamental nature, having a relevant function in achieving legitimacy for government undertaking. It constrains an entity to articulate purposes for the diverse policies for which it is accountable and report the period within which they should be accomplished. The standard of policy and decision-making may be considerably enhanced through performance measurement in entities enforcement. The configuration of the entire measurement process affects the resolution on how to employ performance information has consequences [10].

The performance measurement process varies based on conceived work of performance information. Variegated intrinsic mechanisms explain why responsibility for performance puts pressure on individuals in organizations [10]. At the organizational level, effective performance information systems enable leaders to systematize, enforce and supervise organizational goals. Performance management approaches such as the employment goals and benchmark contests increase the public services strength and have a beneficial impact on results [10]. Performance management at the field level is highly effective, as long as there are adequate comparator entities to allow performance contest and comparative knowledge between entities. Performance management is suitable to provide enhancement in performance indicators that have a prominent level of public recognition [10].

\section{Analysis}

The evaluation process begins with mapping government agencies by a sample of representatives from each type of government agency and each region of Indonesia. The following is a sample of government agencies whose merit system index has been evaluated with achieving scoring with predicate of Very Good and Good meritocracy category. Sampling from government agencies that have implemented the Merit System in Human Resources (HR) Apparatus Management aims to show a model in Performance Management for other agencies that need to receive guidance in managing performance in their agencies.

In addition, this sampling method could thoroughly describe the factual condition, as seen from the gap between agencies with Ideal and Poor HR Management. However, the fact that agencies with a Very Good merit system index are still facing obstacles so that the ideal Performance Management is yet can be applied optimally [7].

In this case, the government agencies mapped as the sample of Very Good and Good merit system index are the Ministry of Finance, National Institute of Public Administration (LAN), West Java Province, Jayapura City, Agam Regency, and Pontianak City [7]. The following are the results of the correlation between the variables of Government Agency (GA) type and merit system (MS) scores values. The excellent integrated system on managing HR Apparatus massively affects the HR performance management in the government agency. Understanding the holistic process of merit system implementation, such as recruiting talented HR leaders and being committed to establishing integrated information systems as a prominent project that would highly affect organizational management, has guided these big government agencies to lead effective HR performance management in their institutions. 
Facing the COVID-19 pandemic which was previously considered as an obstacle has made these institutions produce innovations, specifically in the form of breakthroughs in information systems to help manage organizational dynamics, namely electronic performance (eperformance). The invented innovations are usually in the form of information systems for managing both reporting daily performance evidence, monitoring achievement of individual performance, evaluating performance monthly, checking daily attendance, managing other discipline activities, and performance compensation and other allowances.

Table 1. Correlation between Type of Government Agency (GA) and Merit System Scoring

\begin{tabular}{|l|l|l|l|}
\hline & Mean & Std. Deviation & N \\
\hline GA Type & 17,00 & 3,347 & 6 \\
\hline MS Score & 325,333 & 54,8258 & 6 \\
\hline
\end{tabular}

Table 1 describes that the mean and standard deviation of each variable for government agencies type are as follows: 17 and value of 325,333. The standard deviation is used to determine how close the data from a statistical sample is to the average data of 3.347 and 54.8258 .

Table 2. Correlations between Government Agency (GA) and Merit System Scoring

\begin{tabular}{|l|l|l|l|}
\hline \multicolumn{2}{|c|}{} & GA Type & MS Score \\
\hline \multirow{2}{*}{ Pearson Correlation } & GA Type & 1,000 &, 947 \\
\cline { 2 - 4 } & MS Score &, 947 & 1,000 \\
\hline \multirow{2}{*}{ Sig. (1-tailed) } & GA Type &. &, 002 \\
\cline { 2 - 4 } & MS Score &, 002 &. \\
\hline \multirow{2}{*}{ N } & GA Type & 6 & 6 \\
\cline { 2 - 4 } & MS Score & 6 & 6 \\
\hline
\end{tabular}

The correlation degree between the type of government agency (GA) and merit system (MS) score (Pearson's correlation between MS score and GA type) is 0.947. This means that there are a very high correlation between GA type and MS score. There is a strong relationship between the GA type and MS score. In other words, this means that the decision is acceptable to conclude that there is a significant relationship between GA type and MS Score.

Table 3. Relationship between Government Agency (GA) Type

\begin{tabular}{|l|l|l|l|l|}
\hline Model & $\mathrm{R}$ & R Square & $\begin{array}{l}\text { Adjusted } \\
\text { Square }\end{array}$ & $\begin{array}{l}\text { Std. The error of } \\
\text { the Estimate }\end{array}$ \\
\hline 1 &, $947^{\mathrm{a}}$ &, 896 &, 870 & 1,205 \\
\hline
\end{tabular}

a. Predictors: (Constant), Government Agency Score

There is a coefficient of determination Rsquare $=89.6 \%$ indicating that the variation of the $\mathrm{Y}$ variable can be explained by the $\mathrm{X}$ variable, meaning that the relationship between the independent variable, Merit System Score and the dependent variable, government agency type is $89.6 \%$. The remaining $10.4 \%$ is explained by variables other than the $\mathrm{x}$ variable. 
Table 4. Analysis of Variance

\begin{tabular}{|l|l|l|l|l|l|l|}
\hline \multicolumn{2}{|l|}{ Model } & Sum of Squares & df & Mean Square & F & Sig. \\
\hline \multirow{3}{*}{1} & Regression & 50,188 & 1 & 50,188 & 34,541 &, $004^{\mathrm{b}}$ \\
\cline { 2 - 8 } & Residual & 5,812 & 4 & 1,453 & & \\
\cline { 2 - 7 } & Total & 56,000 & 5 & & & \\
\hline
\end{tabular}

a. Dependent Variable: GA Type

b. Predictors: (Constant), MS Score

Simultaneous $\mathrm{F}$ is calculated at 34,541 with a sign of 0.004 which means that there is a significant relationship between the variables GA Type and MS Score $0.004<0.05$.

Table 5. Regression Equation and Coefficients

\begin{tabular}{|l|l|l|l|l|l|l|}
\hline \multirow{2}{*}{ Model } & \multicolumn{2}{l|l}{$\begin{array}{l}\text { Unstandardized } \\
\text { Coefficients }\end{array}$} & $\begin{array}{l}\text { Standardized } \\
\text { Coefficients }\end{array}$ & T & Sig. \\
\cline { 3 - 8 } \multicolumn{2}{|l}{} & B & Std. Error & Beta & & \\
\hline \multirow{2}{*}{1} & (Constant) & $-1,800$ & 3,236 & &,- 556 &, 608 \\
\cline { 2 - 8 } & MS Score &, 058 &, 010 &, 947 & 5,877 &, 004 \\
\hline
\end{tabular}

a. Dependent Variable: GA Type

Regression equation $=-1,800+0,058 \times$. There is a significant relationship between MS Score with GA Type of 0.004 partially. There are 6 (six) government of agencies, consist of difference level/type of agencies, namely Ministry of Finance, National Institute of Public Administration (LAN), 1 province, West Java Province, Jayapura City, Agam Regency and Pontianak City. All of these government agencies has good and very good merit system scoring. Based on the ongoing process of assessing and fostering the merit system implementation, there are still many government agencies facing impediments to implementing merit-based Performance Management. This is also supported by the variety of field conditions that require different treatment for each agency condition [7].

Moreover, the achievement of performance management implemented in underdeveloped areas surely encounters certain obstacles at various levels. Factual situations related to human resources, technology, and information systems, and financial budgets are seemingly impossible to be ignored. Major partiality between central government agencies, such as ministries and national institutes, and cities or regencies in underdeveloped areas in Indonesia portrays the implementation of HR performance management as an aspect of meritocracy. Merit system implementations in underdeveloped areas comprise cities, regencies, and even provinces in Kalimantan, Sulawesi, Maluku, Papua, and several remote areas in Java [7].

These obstacles and poor implementations are depicted in the ineffectiveness of performance measurement which can be seen from the poorness of Performance Contracts; Performance Appraisal Methods; Performance Dialogues; Gap Performance Analysis; and Use of the Performance Appraisal for Career Development and Decisions. The following analyzes the data from the diagram in implementing Performance Management Policy.

Diagram 1 shows that the acquisition of an assessment where in some places there is still a shortage of scores from the maximum score. Aspects such as performance contracts, application of objective performance appraisal methods, implementation of periodic performance appraisals in which there is a performance dialogue, analyzing performance problems, and using the results of performance appraisals in decisions to carry out sustainable development. 


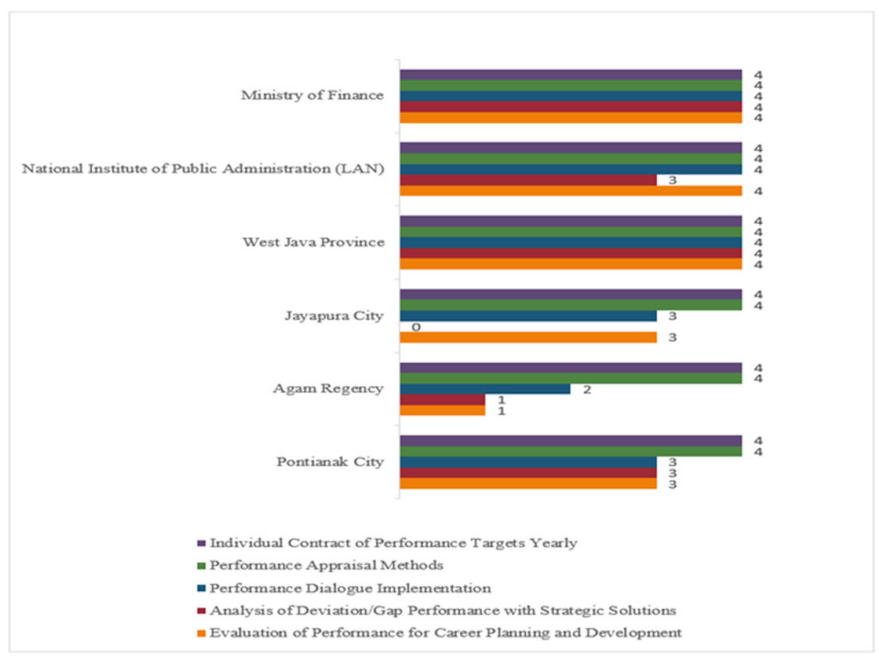

Fig 1. Good Performance Management Implementation from Different Type of Government Agencies in Indonesia (Source: Proceed from SIPINTER directory of KASN

(https://sipinter.kasn.go.id, accessed on 7 August 2021)

Furthermore, Diagram 2 (two) until Diagram 6 (six) provide a more detailed explanation of implementation of performance management aspects, namely:

a. Individual Contract of Performance Targets Yearly (Diagram 2).

b. Performance Appraisal Method (Diagram 3).

c. Performance Dialogue Implementation (Diagram 4).

d. Analysis of Deviation/Gap Performance with Strategic Solutions (Diagram 5).

e. Evaluation of Performance for Career Planning and Development (Diagram 6).

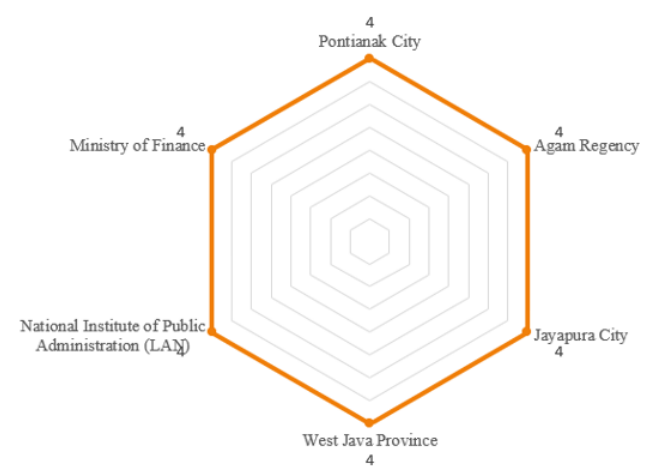

Fig 2. Individual Contract of Performance Targets Yearly (Source: Proceed from SIPINTER directory of KASN)

In the aspect of availability and making performance contracts, it can be seen in the chart above that all agencies have understood and have made performance contracts consisting of the top leadership level to the lowest level, namely the executor, which is derived from the agency's strategic plan. 
The scoring variable is determined in several levels:

a. Obtaining a score of 1 , shows that the creation and availability of performance contracts is only limited to the high level of leadership

b. Obtaining a score of 2 , shows the availability of performance contracts for high lead levels, supervisory levels, and functional levels

c. Obtaining a score of 3 , shows the availability of performance contracts from the high leadership level, supervisor level, functional level to the lowest level, namely the executor.

d. Obtaining a score of 4, indicates the availability of performance contracts for all levels by synchronizing them with the agency's strategic work plan.

Diagram 2 shows that almost all the government agencies which achieved good and very good categories has implemented policy of cascading performance. This means that each individual performance has strong correlation with performance indicators of top, middle and low structural positions or managers and also with its institutions. The achievement of a score of 4 indicating the availability of performance contracts for all levels by synchronizing the agency's strategic work plan in all sample agencies is closely related to the development and use of e-performance as a form of adaptation from the new normal era due to the COVID-19 pandemic.

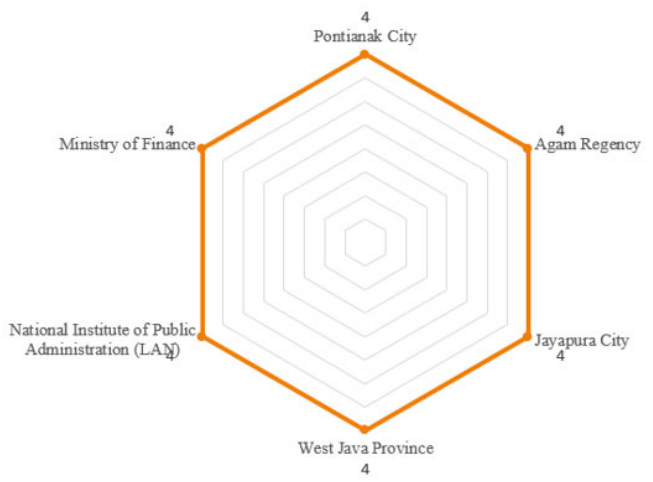

Fig 3. Performance Appraisal Method (Source: Proceed from SIPINTER directory of KASN)

Furthermore, in the aspect of using a measurable and objective performance appraisal method, based on the chart above, it can be found that all agencies have understood and implemented a measurable and objective appraisal method, and the appraisal method has been standardized in the form of internal regulations. The level of determination of the score is determined by the stratified variables as below:

a. Score 1, indicates that the performance has been assessed, but it is not yet fully measurable and objective.

b. Score 2, shows that the performance assessment has been used using a measurable and objective method, but only limited to the leadership level.

c. Score 3, indicates that performance assessment has been used using a measurable and objective method, in leadership positions and supervisory positions as well as functional positions. 
d. Score 4, indicates that the performance assessment has been used with a measurable and objective method at all levels of office, from leadership positions, supervisory positions, functional positions, to executive positions.

Diagram 3 indicates that all agencies with good and very good categories has their own method to evaluate and monitor their personal employees'performance. This means that organisation has provided accurate, objective and precise method to review individual performance of their employees. The accurate and objective method to evaluate individual's performance is important for providing an objective and fair compensation for employees with a high or low performance degree (higher compensation for high performance and lower compensation for low performance).

Similar to the achievements in the implementation of performance contracts, the outcomes of a score of 4 indicating that the performance assessment has been used with a measurable and objective method at all levels of office, from leadership positions, supervisory positions, functional positions, to executive positions in all sample agencies is closely related to the development and use of e-performance as a form of adaptation from the new normal era due to the COVID-19 pandemic.

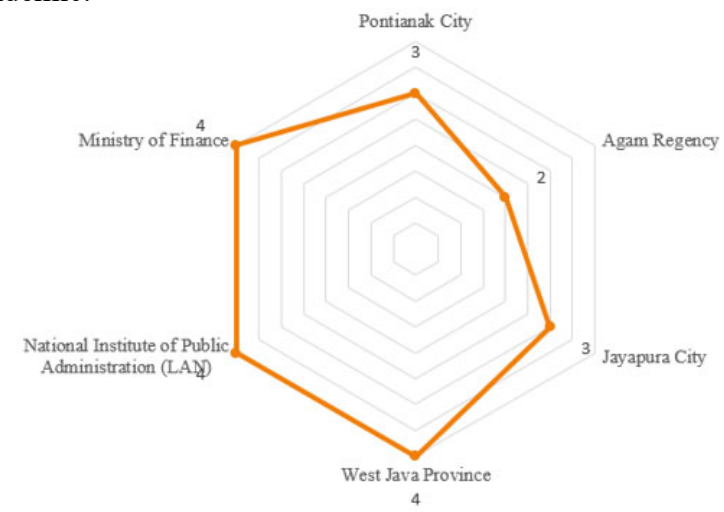

Fig 4. Performance Dialogue Implementation Source: Proceed from SIPINTER directory of KASN

Diagram 4 describes different implementations of performance dialogue, which the Ministry of Finance, National Institute of Public Administration (LAN), and West Java Province, has implemented very well. However, city and regency level of local governments are still learning to provide better dialogue performance model to be implemented in their organisations. The performance dialogue aspect, in its implementation, is carried out simultaneously or after a periodic assessment of the performance is carried out.

The purpose of the performance dialogue is to explore the obstacles in the implementation of the performance contract in the field carried out by the individual concerned, as well as to dig deeper into the potential that exists in the individual for later development with the final result being able to achieve maximum results from the performance contract that has been set. From the chart above, it is known that 3 out of 6 agencies have not received a maximum score of 4 .

The use of performance dialogue in the performance evaluation process still faces many challenges in its implementation. This is because many agencies are currently still in the learning 
process to be able to use performance dialogue appropriately, especially in the city and regency level of local government. The following explains the variables based on the score:

a. Score 1, has carried out a performance appraisal once a year, without any performance dialogue.

b. Score 2, has carried out periodic performance appraisals every 6 months, without any performance dialogue.

c. Score 3, has carried out periodic performance appraisals every 3 months, accompanied by a performance dialogue.

d. Score 4, a performance assessment has been carried out once a month, which is accompanied by a performance dialogue.

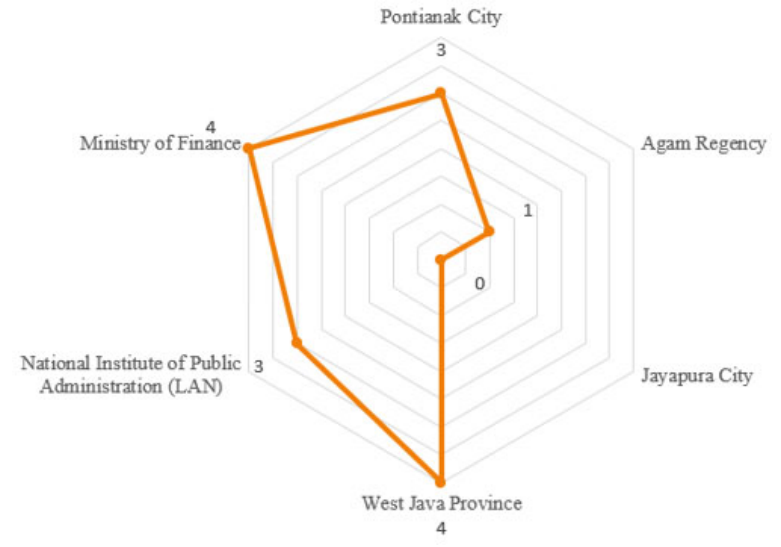

Fig 5. Analysis of Deviation/Gap Performance with Strategic Solutions (Source: Proceed from SIPINTER directory of KASN)

Diagram 5 shows that most of government institutions still have difficulties to provide analysis of individual performance evaluations. Only the Ministry of Finance and West Java Province that has a good performance analysis system with strategic plan to resolve the problems in short, medium and long terms. One of the problems the government institutions could not implement well is due to unavailability of data and information to support. Moreover, they are still learning how to provide program and activities to improve their individual performances through non - classical approaches.

The next aspect is the aspect regarding the availability of information on the analysis of performance problems and the preparation of strategies for solving them to support the realization of the objectives of the agency's strategic plan. In obtaining agency scores shown by the chart above, it shows that not all agencies understand the procedures for compiling and providing information about performance problems and solutions that will be taken to overcome these problems.

The score level is based on the following variables:

a. Score 1, has analysed problems related to performance but has not been structured.

b. Score 2, has analysed performance problems in a structured manner.

c. Score 3 , has analysed performance problems and develop strategies to overcome these problems. 
d. Score 4, has analysed performance problems, developed and implemented strategies to overcome these problems.

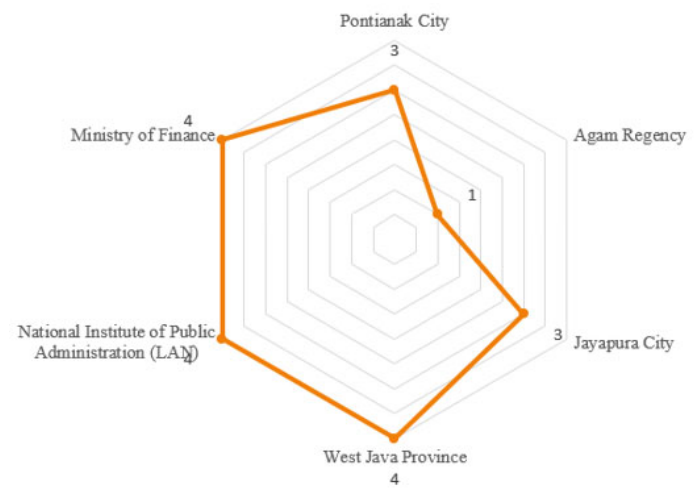

Fig 6. Evaluation of Performance for Career Planning and Development (Source: Proceed from SIPINTER directory of KASN)

The last aspect is about using the results of performance appraisals in deciding career development and coaching. Based on the chart above, not all of them get a maximum score of 4. The score level is determined by the variables as below:

a. Score 1, the results of the performance appraisal become the basis for coaching and career development but are not yet structured.

b. Score 2, the results of the performance appraisal become the basis for structured career coaching and development.

c. Score 3, the results of the performance assessment become the main consideration in coaching and career development.

d. Score 4, the results of the performance appraisal have become one of the aspects used in determining the talent pool.

Our analysis indicates that gap performance analysis as an aspect of performance management in Indonesia substantively as well as statistically need to be taken into consideration in any adequate accounting for results. This explained by as each Government Agency (GA) Types seen altogether, the gap performance analysis aspect generally shows lower Merit System (MS) Score compared to other aspects. Judging from the scattered region in Indonesia, the east region represented by Jayapura City in mostly every aspect is still considered the most lagging behind. Meanwhile, other than the Ministry of Finance, West Java Province as a local government located near the capital is granted the highest Merit System Score which denotes Very Good implementation of performance management.

\section{Conclusion}

As for the solutions which can be applied for performance management issues for a certain area in Indonesia, referring to the case study of Charlotte-Mecklenburg as described by Rusaw and Rusaw [13], the role of Human Resources (HR) Development in crisis management elaborated in this process: 
a. Setting crisis management as a priority;

b. Emphasis on multiple and continuous learning;

c. Developing flexible organizational structures; and

d. Coordinated, decentralized leadership.

Mathis and Jackson [15] argue that HR Department is accountable for forming appraisals, ensuring appraisal is being carried out, coordinating the appraisal process, and ensuring that supervisors are skilled and well trained on the appraisal process. Not only supervisors are responsible for evaluating and reviewing planned and actual performance, but also they are required to be able to give constructive feedback and rate performance according to set and agreed scale, review appraisal with the employee in two-way communication, prepare and hand appraisal report to HR Department.

Mathis and Jackson [15] figure that appraisal methods depend on the distinctive value of achievement of the organizations. Hence, there are no set appraisal methods to be the best way of appraisal. Combined methods of clear standards and purpose of appraisals as well as training of managers and support and guidance of top management would enhance performance evaluations.

The tasks and responsibilities that come most readily to mind about public managing are those tied to public organization concerning the internal functioning: motivating staff, structuring work relationships, organizing tasks, maintaining the budget and other resources such as information systems, appraising individuals' performance, and the like. On other perspective, public management can also be seen from another angle: the externally oriented actions of as managers seek to do their jobs and advance their organization's causes [12].

Networks are contextures of interdependence involving numerous organizations or parts thereof, in which in some larger hierarchical arrangement one unit is not merely the formal subordinate of the others. Networks demonstrates some structural stability but expand beyond policy-legitimated ties and formally established linkages. The institutional networked ties may enclose authority bonds, exchange relations, and coalitions based on mutual concern, all within a multi-unit structure [12].

Before policy learning could occur, governments can learn from each other's experiencing difficulties in order to avoid mistakes to be repeated in many places. This would contribute to governments adjusting with critical issues and thorny policy challenges such as protecting against disease, encouraging economic growth, building and maintain infrastructure, educating young people, providing social security, and so many more. Collaborations within talented policy designers and policy analysts will grant many of these complex tasks less daunting [12].

\section{References}

[1] Ministerial Regulation of Administrative and Bureaucratic Reform number 24 of 2020 about Strategic Plan of Bureaucratic Reforms for 2020-2024, 2020.

[2] KASN, Pemetaan Penerapan Sistem Merit dalam Manajemen Aparatur Sipil Negara (ASN), Jakarta: Komisi Aparatur Sipil Negara, 2018.

[3] Ministerial Regulation of Administrative and Bureaucratic Reform number 40 of 2018 about Guidelines for Merit System as Human Resources Apparatus Management, 2018.

[4] Regulation of Indonesian Civil Service Commission (KASN) Number 3 of 2020 about Strategic Plan of Indonesian Civil Service Commission for 2020-2024, 2020.

[5] Law Number 5 of 2014 about Human Resources Apparatus, 2014. 
[6] S. Dwiputrianti, „Challenges with Implementation of the Merit System in the Open Recruitment of Government High Positions: The Case in Indonesia,“ Advances in Social Science, Education and Humanities Research, zv. 191, 2018.

[7] Information Systems of Self-Assessment of Merit System Implementation (SIPINTER) directory of KASN.. Available: http://www.sipinter.kasn.go.id/. [Cit. 2021].

[8] Ministerial Regulation of Administrative and Bureaucratic Reform number 8 of 2021 about Performance Management System, 2021.

[9] I. C. Davies, „Evaluation and Performance Management in Government,“ Evaluation, pp. 150-159, 1999.

[10] D. P. Ljungholm, „The Practice of Performance Management in Public Sector Organizations,“ Geopolitics, History, and International Relations, pp. 190-196, 2015.

[11] Regulation of Indonesian Civil Service Commission (KASN) Number 9 of 2019 about Procedures for Self-Assessment of the Merit System in the Management of the State Civil Apparatus (ASN), 2019.

[12] L. J. O'Toole Jr a K. J. Meier, Public Management: Organizations, Governance, and Performance, New York: Cambridge University Press, 2011.

[13] A. C. Rusaw a M. F. Rusaw, ,The Role of HRD in Integrated Crisis Management: A Public Sector Approach," Advances in Developing Human Resources, pp. 380-396, 2008.

[14] Sedarmayanti, Mulyaningsih, T. Listiani, S. Dwiputrianti a A. Meryanti, Membangun Karakter, Kepribadian, Talenta, dan Inovasi di Era Revolusi Industri 4.0 dan Masyarakat 5.0, Yogyakarta: Deepublish Publisher, 2021.

[15] D. Mpabanga, „Performance Monitoring and Evaluation in Botswana's Public Service: Achievements and Challenges, “ Africa's Public Service Delivery \& Performance Review, pp. 50-93, 2016. 